\title{
THE EFFECT OF ECOLOGICAL SITE PROPERTIES ON THE MAJOR ESSENTIAL OIL COMPONENTS OF THE CRIMEAN JUNIPER LEAVES
}

\author{
GÜLSOY, S.*-MERDIN, A. \\ Faculty of Forestry, Isparta University of Applied Sciences, 32260 Isparta, Turkey \\ (phone: +90-505-547-0196; fax: +90-246-211-3948) \\ *Corresponding author \\ e-mail: srkngulsoy@gmail.com \\ (Received 31 ${ }^{\text {st }}$ Jul 2018; accepted 28 ${ }^{\text {th }}$ Sep 2018)
}

\begin{abstract}
This study explores the relationship between environmental factors and the main essential oil components in the leaves of Crimean juniper (Juniperus excelsa M. Bieb.), which is commonly distributed in rocky and stony land with shallow soil conditions in the Mediterranean region of Turkey. After the leaf samples collected from 20 plots were dried, essential oil components were detected by GCMS method. $\alpha$-Pinene $(81.3 \%)$, myrcene $(5.2 \%)$ and limonene $(4.5 \%)$ were found to be the major components, respectively. Relations between these major components and environmental factors (physiographic, climatic and soil factors) were questioned by Pearson correlation analysis, cluster analysis and principal component analysis. According to statistical analysis results; $\alpha$-pinene bio18, altitude and $\mathrm{pH}$ were found to have a negative relationship. The limonene component showed a negative relationship with latitude and clay, but showed a positive correlation with $\mathrm{pH}$.
\end{abstract}

Keywords: environmental factors, climate, principal component analysis, major components, Mediterranean region

\section{Introduction}

Due to various biochemically active substances contained by their miscellaneous organs such as leaves, cones, bark, roots and flowers, the taxa of juniper are amongst the important medicinal and aromatic plant species distributed in forests (Topçu et al., 2005). Therefore, it has been used by people not only as food and spice but also for multiple purposes such as beverage, perfumery, cosmetics, aromatherapy and medicine for treatment of some diseases since ancient times (Ložienė and Venskutonis, 2016). With the development of new technologies in recent years, juniper species just like many other medicinal and aromatic plant species can now be processed with more modern techniques and they can be used more comprehensive in different forms, e.g. such as food, medicine, pharmaceuticals and cosmetics (Faydaoğlu, and Sürücüoğlu, 2011).

It is possible to explain properties of the medical and aromatic plants with the biochemical substances they contain. Juniper species are characterized by intense essential oils they contain in different organs, and several volatile components in the essential oils. Therefore, many studies have been conducted in the scientific literature regarding the essential oil yield and components of juniper species in recent years (Bakkour et al., 2013; Höferl et al., 2014; Fejér et al., 2018).

In Turkey's forests, which cover an area of around 22.3 million hectares, juniper species are represented by 11 different taxa in 7 species belonging to 3 different sections (Fakir, 2014). In Turkey, out of these taxa, Juniperus excelsa M. Bieb. (Crimean juniper) has the widest distribution area (Göze et al., 2017). Around the 
world, it is distributed in Macedonia, Aegean and Greek Islands, Asia Minor and Caucasia; while it has the widest distribution especially in the Mediterranean Region and Western Taurus range in Turkey. The distribution range of Crimean juniper extends through the steppe areas into the inner parts of Anatolia. The anthropogenic impacts throughout the history resulted in the destruction of this species in the Mediterranean forest (Fontaine et al., 2007). On the other hand, the seed dormancy and germination problems which are considered to be a general juniper-related issue has led to challenges in the regeneration of Crimean juniper in natural habitats until recently (Gülsoy and Özkan, 2013).

Crimean juniper is of ecological importance for Turkey's forests and has been used in food, pharmaceutical, medicine, preservation and perfume industries due to several chemical substances they contain in their cones, leaves and barks such as other juniper species. It is known that especially the essential oils this species contains in its organs, add value to the plant in medicinal and aromatic terms. The products such as juniper oils and juniper essence that are obtained through distillation from various organs are reported to add industrial value to this species. In particular, the extracts of the species is expressed to be the effect of anti-inflammatory, anti-microbial, antiseptic, antitermite, insecticide, hypotensive, diuretic, antioxidant, antibacterial and antispasmodic (Moein et al., 2010; Orhan, et al., 2012; Adams et al., 2013; Göze et al., 2017).

As one can understand from the abovementioned information, Crimean juniper is an important forest tree species but also a crucial plant with its biochemical substances. Therefore, there are many studies in the literature regarding various biochemical substances of the species and its medicinal-aromatic properties. However, there is no study that explores the relationship between the ecology of the species and the main essential oil components it contains. Nevertheless, it is argued that the biochemical properties of plants vary depending on different methods applied, which part of the plant is used, maturity period, growing method and genetic factors as well as ecological conditions (Gende et al., 2010). This study aimed to identify the ecological habitat conditions of this species distributed in the Lakes District in the Mediterranean Region of Turkey. Another important intention of the study was to introduce the interactions between the environmental factors and the major essential oil components. Thus, the study aimed at obtaining significant information about the impacts on the essential oil components in the leaves depending on the ecological site conditions of this species. It is suggested that the results of this study will lead to further scientific studies on this topic.

\section{Material and methods}

\section{Study area}

This study was conducted at 20 Crimean juniper sites selected is located within the Lakes District extending from $38^{\circ} 25^{\prime}-36^{\circ} 06$ northern latitudes and $29^{\circ} 30^{\prime}-32^{\circ} 34^{\prime}$ eastern longitudes in the southwest of Turkey (Fig. 1).

The predominant bedrock formations in the study area are mainly limestone and dolomite. The main soil types are red, brown or reddish-brown forest soils of the terrarossa type developed on karst landforms that lead to variations in soil characteristics in the district (Sandler et al., 2015). Soil depth is generally thin with a thickness of 0$40 \mathrm{~cm}$ on slopes and rarely deep a thickness of up to $100 \mathrm{~cm}$ in depressions. According to the data recorded for many years in the region, the average annual rainfall is 
approximately $600-1300 \mathrm{~mm}$ and the average annual temperature varies between 12 $20{ }^{\circ} \mathrm{C}$. A subtropical Mediterranean climate generally characterized by hot and dry summer months and warm wet winter months prevails in coastal zones near the Mediterranean Sea, low-altitude locations and the sea-facing slopes of the mountains, while the transition climate from Mediterranean climate to continental climate is observed in areas distant from the sea and at higher elevations (Benli, 2016).

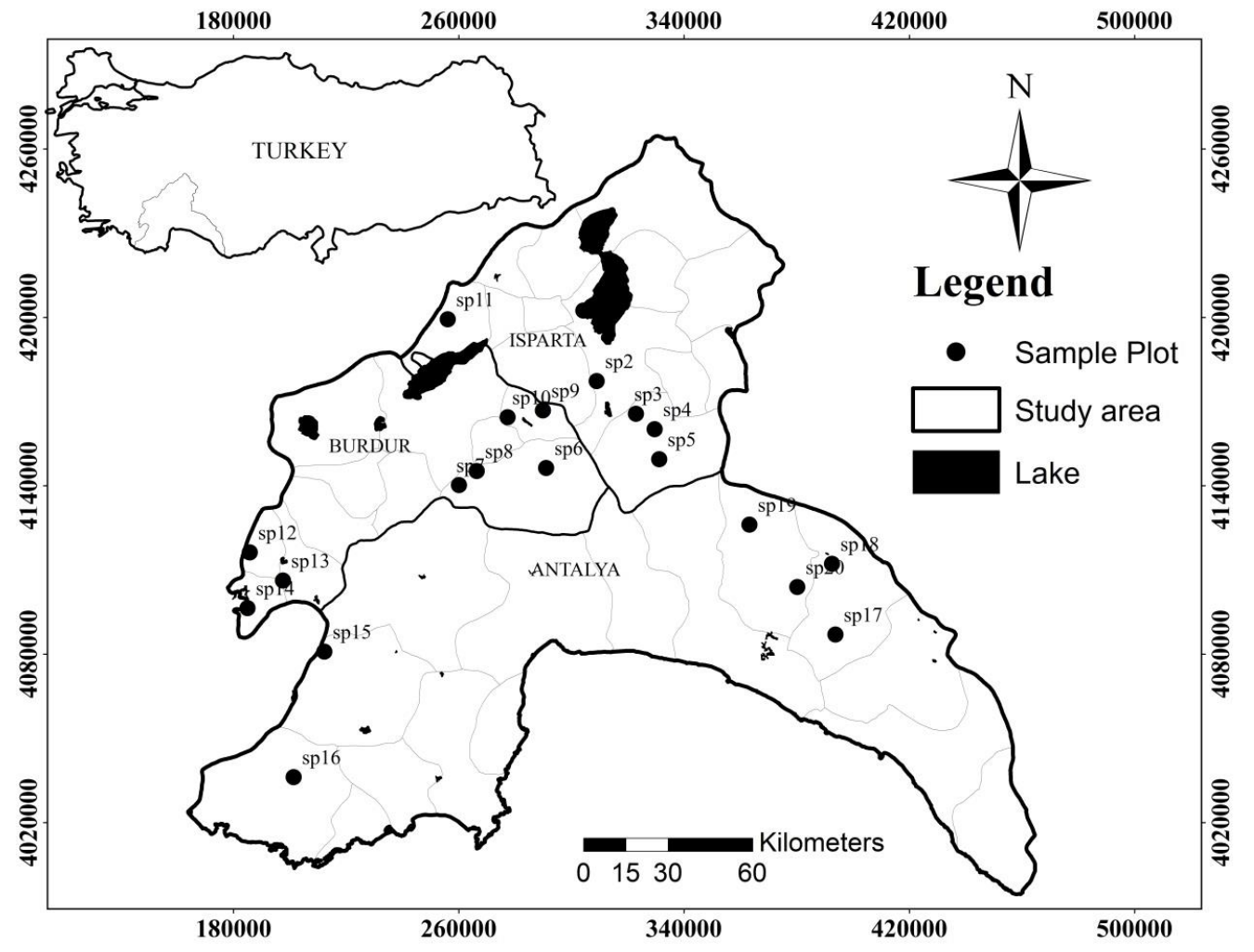

Figure 1. Location map of the sample plots in the study area

\section{Data collection}

Crimean juniper leaves used in this study were obtained from 20 sampling plots in the Lakes District of Turkey. These plots were selected from the sites free from human impact, fungal and insect damage. Leaves samplings were collected from the last year's shoots on the northern aspects of the plants. In addition to leaf sampling, several ecological measurements were conducted in each sampling plot in order to find the associations of the essential oil components to be derived from the leaves with environmental factors. First, latitude, longitude and elevation $(\mathrm{m})$ values were recorded using GPS while the aspect of hillside $\left(^{\circ}\right)$ was recorded using a compass and the slope (\%) was measured with a clinometer. The surface stoniness (\%) of the land was estimated using the iron rod penetration method at 10 points randomly selected within each sampling plot (Eriksson and Holmgren, 1996). Furthermore, landform and slope position were recorded through observations in the sampling plots. The depth of the mineral soil was measured in hand-excavated pits and bedrock formations were determined from geological maps compiled by General Directorate of Mineral Research and Exploration. 
The climate maps were obtained from the database developed by Fick and Hijmans (2017) at global scale and edited with the Global Mapper at the local scale. The boundaries of the sampling plots were matched with the pixels of the maps of climate variables according to the GPS coordinates, climate data for each plots were obtained from these maps.

Before the statistical assessments, a digital elevation model (DEM) was created from the topographic database. Radiation index, heat index and topographic position index for each sampling plot were calculated using this DEM. At this stage; the radiation index equation (Eq. 1)

$$
R I=\frac{[1-\cos ((\pi / 180)(Q-30))]}{2}
$$

that can be applied to intermediate distance from equator line to $60^{\circ}$ north latitude, slope degree less than $90^{\circ}$, and all aspects of hillsides was used (McCune and Keon, 2002). RI varies between 0 and 1, and the approximation of this value to 1 indicates the long duration of sunshine in the plot. Then, heat index values with Equation 2:

$$
\mathrm{HI}=1+\cos \left(\left(45^{\circ} \text {-aspect degree }\right) / \text { slope degree }\right)
$$

were calculated (Beers et al., 1966). HI varies between -1 and 1, and the approximation of this value to 1 indicates hotter points in the field.

The elevation value of the pixel on which the sampling plot is located on the map and the elevation differences of the other pixels adjacent to that sampling plot were used to calculate the topographic position index (TPI) values for each sampling plot (Weiss, 2001). Last, the distance between the sampling plots and the borders of the lakes and sea located in the study site was calculated on the basis of the distance that would result from the landform on DEM. For this step, ArcMap 10.2 software was used. For both measurements, "distance point to line/polygon" command was used for measurements in each sampling plot on the basis of the closest polygon and line to the points (Mert et al., 2013).

The soil samples $(0-5 \mathrm{~cm})$ were taken among of the trees from which leaf samples were collected in the field. After the soil samples were air-dried and ground, they were passed through the sieve $(2 \mathrm{~mm})$. The soils were analysed at the Laboratory of Süleyman Demirel University Faculty of Agriculture - Soil Department. Particle size of the soils was determined by using Bouyoucos's hydrometer method (Bouyoucos, 1951). Field capacity was measured by a pressure plate device (Cassell and Nielson, 1986). Soil $\mathrm{pH}$ level was determined through $\mathrm{pH}$ metre with glass electrode according to Jackson (1958). In addition, organic matter content in soils was determined by modified Walkley-Black method according to Jackson's procedure (1958). The carbonate contents $\left(\mathrm{CaCO}_{3}\right)$ in soil samples were measured with a Scheibler Calcimeter using volumetric method (Bush, 1970). Finally, after saturating soils with Na-acetate, they were extracted with ammonium acetate and the extracted sodium was read in the atomic absorption spectrophotometer and their cation exchange capacity was found (Chapman, 1965).

As a result 42 different environmental variables were identified and codes with maximum 6 characters were assigned to these variables for statistical assessment (Table 1). 
Table 1. Variables used during statistical analysis and the assigned codes

\begin{tabular}{|c|c|c|c|c|c|}
\hline Variables & Code & Variables & Code & Variables & Code \\
\hline Latitude & latitu & $\mathrm{pH}$ & $\mathrm{pH}$ & Distance to nearest sea border (km) & nsea \\
\hline Longitude & lngitu & Lime & lime & Annual mean temperature $\left({ }^{\circ} \mathrm{C}\right)$ & bio1 \\
\hline Elevation (m) & elvtn & Organic matter $(\%)$ & orgmat & Max temperature of warmest month $\left({ }^{\circ} \mathrm{C}\right)$ & bio5 \\
\hline Slope degree $\left(^{\circ}\right)$ & slope & Electrical conductivity (dScm-1) & ec & Min temperature of coldest month $\left({ }^{\circ} \mathrm{C}\right)$ & bio6 \\
\hline Radiation index & $\operatorname{rdin} x$ & Cation exchange capacity (me/100 g) & cec & Mean temperature of wettest quarter $\left({ }^{\circ} \mathrm{C}\right)$ & bio8 \\
\hline Surface stoniness $(\%)$ & surfst & Sodium $\mathrm{Na}+(\mathrm{me} / 100 \mathrm{~g})$ & na & Mean temperature of driest quarter $\left({ }^{\circ} \mathrm{C}\right)$ & bio9 \\
\hline Soil depth & sdepth & Potassium K+ (me/100 g) & $\mathrm{k}$ & Mean temperature of warmest quarter $\left({ }^{\circ} \mathrm{C}\right)$ & bio10 \\
\hline Land surface shape & lshape & Calcium $\mathrm{Ca}++(\mathrm{me} / 100 \mathrm{~g})$ & $\mathrm{ca}$ & Mean temperature of coldest quarter $\left({ }^{\circ} \mathrm{C}\right)$ & bio11 \\
\hline Slope position & sposit & Magnesium Mg++ (me/100 g) & $\mathrm{mg}$ & Annual precipitation (mm) & bio12 \\
\hline Landform & landfm & Field capacity (\%) & fieldc & Precipitation of wettest month (mm) & bio13 \\
\hline Bedrock formation & bedrck & Wilting point $(\%)$ & wiltpo & Precipitation of driest month (mm) & bio14 \\
\hline Sand $(\%)$ & sand & Topographic position index & tpi & Precipitation of wettest quarter (mm) & bio16 \\
\hline Clay $(\%)$ & clay & Heat index & hindx & Precipitation of driest quarter (mm) & bio17 \\
\hline Silt $(\%)$ & silt & Distance to the nearest lake $(\mathrm{km})$ & nlake & Precipitation of warmest quarter (mm) & bio18 \\
\hline
\end{tabular}

The leaves collected from the field were stored to air-dry for 2 months under laboratory conditions in summer period of 2015. Then, the air-dried samples were placed in metal containers and dried in oven at $35{ }^{\circ} \mathrm{C}$ until reaching a constant weight. The adsorption of essential oil components was carried out using Solid Phase Microextraction Technique (SPME) by a fibre (Spietelun et al., 2013). For desorption of essential oil components, fibre was immersed onto injection port for 5 more minutes. The percentage of the essential oil components were determined by Gas Chromatography-Mass Spectrometry (GC/MS) analysis. In the GC/MS device, the column temperature was started at $40{ }^{\circ} \mathrm{C}$ for $2 \mathrm{~min}$. It was then heated to $250{ }^{\circ} \mathrm{C}$ with an increase rate of $4{ }^{\circ} \mathrm{C}$ per minute and kept at $250{ }^{\circ} \mathrm{C}$ for $5 \mathrm{~min}$.

\section{Statistical analysis}

During statistical assessments, factor analysis was firstly performed for the bioclimate variables considered to have a high correlation probability. In order to determine the bilateral relationships between the environmental variables and major essential components, Pearson Correlation Analysis was applied. To determine how the sampling plots were grouped in terms of the major components, cluster analysis was performed (Sarstedt and Mooi, 2014). Finally, Principal Components Analysis (PCA) was applied to identify the direction of the relationships between the major essential oil components that were the dependent variables and the environmental factors that were the independent variables (Bro and Smilde, 2014). SPSS Version 21.0 and PC-ORD Version 6.0 software were used in statistical analysis process.

\section{Results and discussion}

The mean elevation of 20 sampling plots selected at different locations was $1273 \mathrm{~m}$, while the elevation of the highest sampling plot was $1920 \mathrm{~m}$ and that of the lowest sampling plot was $475 \mathrm{~m}$. The mean inclination of the sampling plots was 27 degrees with plots consisting of both flat and steep inclination. The radiation index values ranged from 0.005 to 0.999 . The topographic position index of the sampling plots varied from -0.438 to 0.954 . The heat index values ranged from 0.013 to 2.00 . As for the 
landforms of the sampling plots, $40 \%$ had flat terrain while $60 \%$ had undulating terrain. $55 \%$ of the sampling plots were located on upper slopes, $20 \%$ were located on medium slopes, $15 \%$ were located on lower slopes and $10 \%$ were on bottom lands. According to the landform characteristics, 2 different types of data were recorded in the study site, out which $90 \%$ were rocky and stony while $10 \%$ were flat. The mean stoniness percentage of the sampling plots was found to be $47.8 \%$. With regard to the bedrock characteristics, limestone was dominant $(80 \%)$ in the areas where $J$. excelsa was distributed.

Depth of the sampling plots ranged from $4 \mathrm{~cm}$ to $120 \mathrm{~cm}$ with a mean soil depth of $46 \mathrm{~cm}$. The results of the chemical analysis conducted on topsoil $(0-5 \mathrm{~cm})$ samples revealed that the percentage of sand in the sampling plots ranged from $16.5 \%$ to $54.4 \%$, percentage of clay ranged from $4.7 \%$ to $44.2 \%$, while the dust percentage ranged from $25.9 \%$ to $52.9 \%$ according to the texture analysis. As for the acidity-alkalinity of the soils sampled from the sampling plots, $\mathrm{pH}$ value ranged from 7.1 to 8.5 . With regard to the lime content $\left(\mathrm{CaCo}_{3}\right)$ of the soil, it was found the highest with $68.9 \%$ in one of the sampling plots, while it ranged from $1.29 \%$ to $6.72 \%$ at the other sampling plots. The amount of organic matter ranged from $2.7 \%$ to $13.4 \%$. The mean cation exchange capacity (CEC) of the soils collected from 20 sampling plots was found to be $55.8 \mathrm{me} / 100 \mathrm{~g}$. The lowest cation exchange capacity was found to be $19.5 \mathrm{me} / 100 \mathrm{~g}$, while the highest was $102.8 \mathrm{me} / 100 \mathrm{~g}$. Average field capacity of the soils collected from the sampling plots was $36.8 \%$. The lowest field capacity was found to be $21.7 \%$, while the highest was found $56.7 \%$. The exchangeable cations from the biggest to the smallest in the soils collected from the sampling plots were $\mathrm{Ca}^{++}(85.5 \mathrm{me} / 100 \mathrm{~g}), \mathrm{Na}^{+}(16.2$ $\mathrm{me} / 100 \mathrm{~g}), \mathrm{Mg}^{++}(9.3 \mathrm{me} / 100 \mathrm{~g})$ and $\mathrm{K}^{+}(8.9 \mathrm{me} / 100 \mathrm{~g})$.

With regard to a total of 41 essential oil components obtained from the leaves of $J$. excelsa, $\alpha$-pinene was the component with the highest amount with a mean value of $81.3 \% \mathrm{v} / \mathrm{w}$. $\alpha$-pinene was followed by myrcene with $6.2 \% \mathrm{v} / \mathrm{w}$ and limonene with $4.5 \%$ $\mathrm{v} / \mathrm{w}$ (Gülsoy and Merdin, 2017). The total percentage of the remaining 38 component was $8.0 \% \mathrm{v} / \mathrm{w}$, therefore, $\alpha$-pinene, myrcene and limonene were defined as the primary essential oil constituents in the leaves of Crimean juniper.

If there is a very high correlation between the independent variables, explaining the relations in the environment becomes a complex. The bio-climate data used in this study are highly correlated with each other. By applying factor analysis, climate variables with the highest correlation coefficient with the components can be determined. As a result of this process, relationships are made through these representative variables. Other climate parameters are evaluated with an indirect interpretation. For this purpose, factor analysis was applied among the bio-climate variables in this study.

The factor analysis applied to bio-climate variables revealed that bio12 and bio18 variables had the highest correlation coefficient. Therefore, only these two variables were used in the subsequent statistical assessment as they had the highest explanation capacity instead of using all bio-climate variables (Table 2).

The correlation analysis applied to the relationship between the environmental variables and major essential oil components revealed that $\alpha$-pinene had a negative correlation with elevation $(\mathrm{r}=-0.505)$ and bio18 $(\mathrm{r}=-0.451)$. Limonene, however, had a negative correlation with latitude $(r=-0.526)$. Myrcene did not have any statistically significant correlation with any environmental factors. Finally, $\alpha$-pinene that was subjected to correlation analysis with soil variables had a statistically significant negative correlation with $\mathrm{pH}(\mathrm{r}=-0.444)$ while limonene had a negative correlation with 
clay $(\mathrm{r}=-0.475)$ and a positive correlation with $\mathrm{pH}(\mathrm{r}=0.448)$. Myrcene showed no significant relationship with any of the soil variables.

Table 2. The correlation coefficients of the variables according to the factor analysis applied to the bio-climate variables on component 1 and component 2

\begin{tabular}{c|c|c}
\hline Variables & Component 1 & Component 2 \\
\hline bio1 & 0,940 & $-0,300$ \\
bio5 & 0,744 & $-0,624$ \\
bio6 & 0,943 & $-0,199$ \\
bio8 & 0,948 & $-0,276$ \\
bio9 & 0,939 & $-0,332$ \\
bio10 & 0,926 & $-0,37$ \\
bio11 & 0,948 & $-0,276$ \\
bio12 & 0,657 & $\mathbf{0 , 7 3 6}$ \\
bio13 & 0,714 & 0,690 \\
bio14 & $-0,921$ & $-0,012$ \\
bio16 & 0,715 & 0,691 \\
bio17 & $-0,902$ & $-0,048$ \\
bio18 & $\mathbf{- 0 , 9 5 4}$ & $-0,098$ \\
bio19 & 0,715 & 0,691 \\
\hline
\end{tabular}

After the correlation and factor analyses, cluster analysis (according to Jacard index and Flexible Beta (=0.25) Cluster Group Linkage Method) was performed in order to find out how the amount of major components were grouped on the basis of the sampling plots. The dendrogram showing the groups of sampling plots according to the cluster analysis is presented in Figure 2.

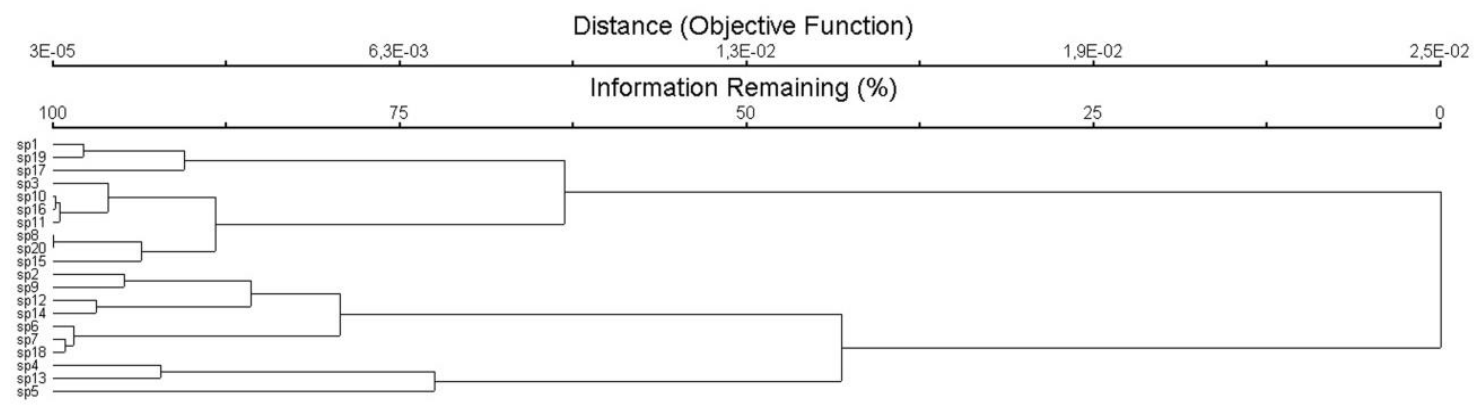

Figure 2. Dendrogram showing the cluster analysis applied to the major essential oil components (sp: sample plot)

The dendrogram shows that division starts at the division line of $40 \%$, after which the sampling plots were clearly divided into 2 groups. 10 sampling plots were in cluster group 1 (sp1, sp3, sp8, sp10, sp11, sp15, sp16, sp17, sp19, sp20), while the other 10 sampling plots were in cluster group 2 (sp2, sp4, sp5, sp6, sp7, sp9, sp12, sp13, sp14, sp18). This suggests that this might be due to the different effects of locations on major essential oil components. Therefore, in order to determine to what extent this difference between the locations was represented by the environmental variables of the sampling 
plots, PCA was conducted. Through the analysis, the eigenvalues of the axes, variance percentages and percentage values of cumulative variance were calculated (Table 3).

Table 3. Eigenvalues of the axes and variance percentages in the PCA applied to major essential components

\begin{tabular}{c|c|c|c|c}
\hline Eigenvalue & \% of variance & Cumulative\% of variance & Broken-stick eigenvalue & Eigenvalue \\
\hline Axis1 & $\mathbf{1 , 8 0 7}$ & $\mathbf{6 0 , 2 4 9}$ & $\mathbf{6 0 , 2 4 9}$ & $\mathbf{1 , 8 3 3}$ \\
Axis2 & 0,886 & 29,531 & 89,780 & 0,833 \\
Axis3 & 0,307 & 10,220 & 100,00 & 0,333 \\
\hline
\end{tabular}

The prerequisite to interpret the axis values found through the PCA analysis is that the eigenvalue coefficient of the relevant axis is smaller than the Broken-stick eigenvalue coefficient. Table 3 shows that Axis1 which explains $60.2 \%$ of the total variance fulfils this criterion. In Axis 2, however, the Broken-stick eigenvalue coefficient explains $29.5 \%$ of the total variance although its numerical value is higher than the eigenvalue. These two axes together explain $89.7 \%$ of the total variance. Therefore, it would be right to make an interpretation principally over Axis 1 and partially over Axis 2 in order to explain the associations during the PCA applied between the major components and environmental variables.

The correlation coefficients of Principal Component Axes with major essential oil components (Pearson and Kendall correlations) are presented in Table 4.

Table 4. Eigenvalues of the axes and variance percentages in the PCA applied to major essential components

\begin{tabular}{c|c|c}
\hline Major components & Axis1 & Axis2 \\
\hline & $\mathbf{r}$ & $\mathbf{r}$ \\
$\alpha$-pinene & $\mathbf{0 . 7 1 0}$ & $\mathbf{0 . 6 4 8}$ \\
Myrcene & $\mathbf{- 0 . 6 8 4}$ & $\mathbf{0 . 6 8 2}$ \\
Limonene & $\mathbf{- 0 . 9 1 4}$ & -0.007 \\
\hline
\end{tabular}

The table shows that $\alpha$-pinene (r:0.710) which was the most intense components in the leaves of Crimean juniper had a significantly positive correlation with Axis 1, limonene (r:-0.914) and myrcene (r:-0.684) had a negative correlation with the same axis. On the other hand, $\alpha$-pinene (r:0.648) and myrcene (r:0.682) had a positive correlation with Axis 2.

Data matrixes regarding the physiographical-climate and soil variables developed to determine the correlations between the essential oil components and environmental factors were transferred to the PCA separately. First, the correlation between the physiographical-climate variables and major components was determined (Table 5).

The results showed that latitude (r:0.506) had the highest correlation with PCA Axis 1, while topographic position index (r:-0.499), elevation (r:-0.469) and precipitation of the hottest quarter (r:-0.457) had the statistically highest correlation with Axis 2. A simple interpretation on Axis 1 reveals that $\alpha$-pinene's intensity increased in the plants in areas where latitude rose, while to the contrary myrcene and limonene decreased. The interpretation made on Axis 2 showed that myrcene and $\alpha$-pinene decreased in areas 
where elevation, topographic position index and precipitation of the hottest quarter increased. Results of the correlations of the major components on the ordination indices are shown in Figure 3.

Table 5. Correlation coefficients between physiographical climate factors and PCA Axis 1-2

\begin{tabular}{c|c|c}
\hline Variables & Axis1 & Axis2 \\
\hline & $\mathbf{r}$ & $\mathbf{r}$ \\
latitu & $\mathbf{0 . 5 0 6}$ & -0.048 \\
lngitu & 0.002 & -0.229 \\
elvtn & -0.328 & $\mathbf{- 0 . 4 6 9}$ \\
nlake & 0.264 & 0.245 \\
nsea & -0.007 & -0.230 \\
slope & 0.244 & 0.073 \\
rdinx & 0.044 & -0.162 \\
surfst & 0.099 & 0.226 \\
lshape & 0.119 & 0.156 \\
sposit & -0.024 & 0.32 \\
landfm & -0.044 & 0.22 \\
hindx & -0.157 & 0.273 \\
tpi & -0.061 & $\mathbf{- 0 . 4 9 9}$ \\
bio12 & 0.323 & 0.024 \\
bio18 & -0.249 & $\mathbf{- 0 . 4 5 7}$ \\
\hline
\end{tabular}
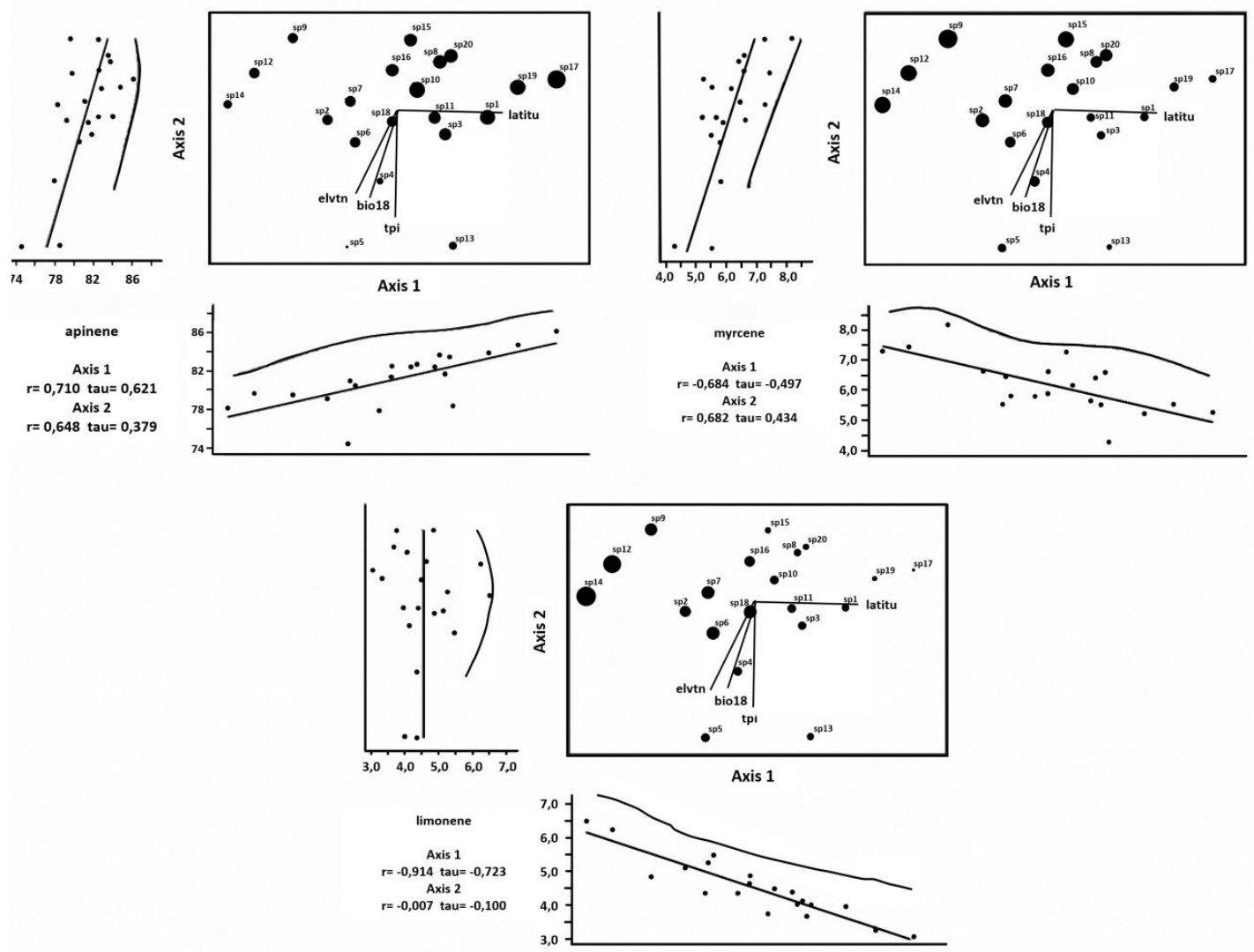

Figure 3. Correlation between major essential oil components and physiographical-climate factors on PCA Axis 1-2 
The correlation coefficients between Axis 1-2 and soil factors are presented in Table 6 and the ordination graphs of the sampling plots according to these correlations are shown in Figure 4.

Table 6. Correlation coefficients between the soil characteristics and PCA Axis 1-2

\begin{tabular}{c|c|c}
\hline Variables & Axis1 & Axis2 \\
\hline sand & $\mathbf{r}$ & $\mathbf{r}$ \\
clay & -0.366 & 0.159 \\
silt & $\mathbf{0 . 4 3 0}$ & -0.025 \\
sdepth & 0.100 & -0.235 \\
bedrck & 0.050 & 0.113 \\
pH & 0.108 & -0.024 \\
lime & -0.032 & -0.008 \\
orgmat & 0.079 & -0.058 \\
ec & -0.041 & -0.151 \\
cec & 0.270 & -0.118 \\
na & -0.277 & -0.081 \\
k & -0.148 & -0.114 \\
ca & 0.056 & $\mathbf{- 0 . 4 8 0}$ \\
mg & -0.176 & -0.042 \\
fieldc & -0.008 & -0.299 \\
wiltpo & 0.018 & -0.072 \\
& -0.142 & -0.113 \\
\hline
\end{tabular}
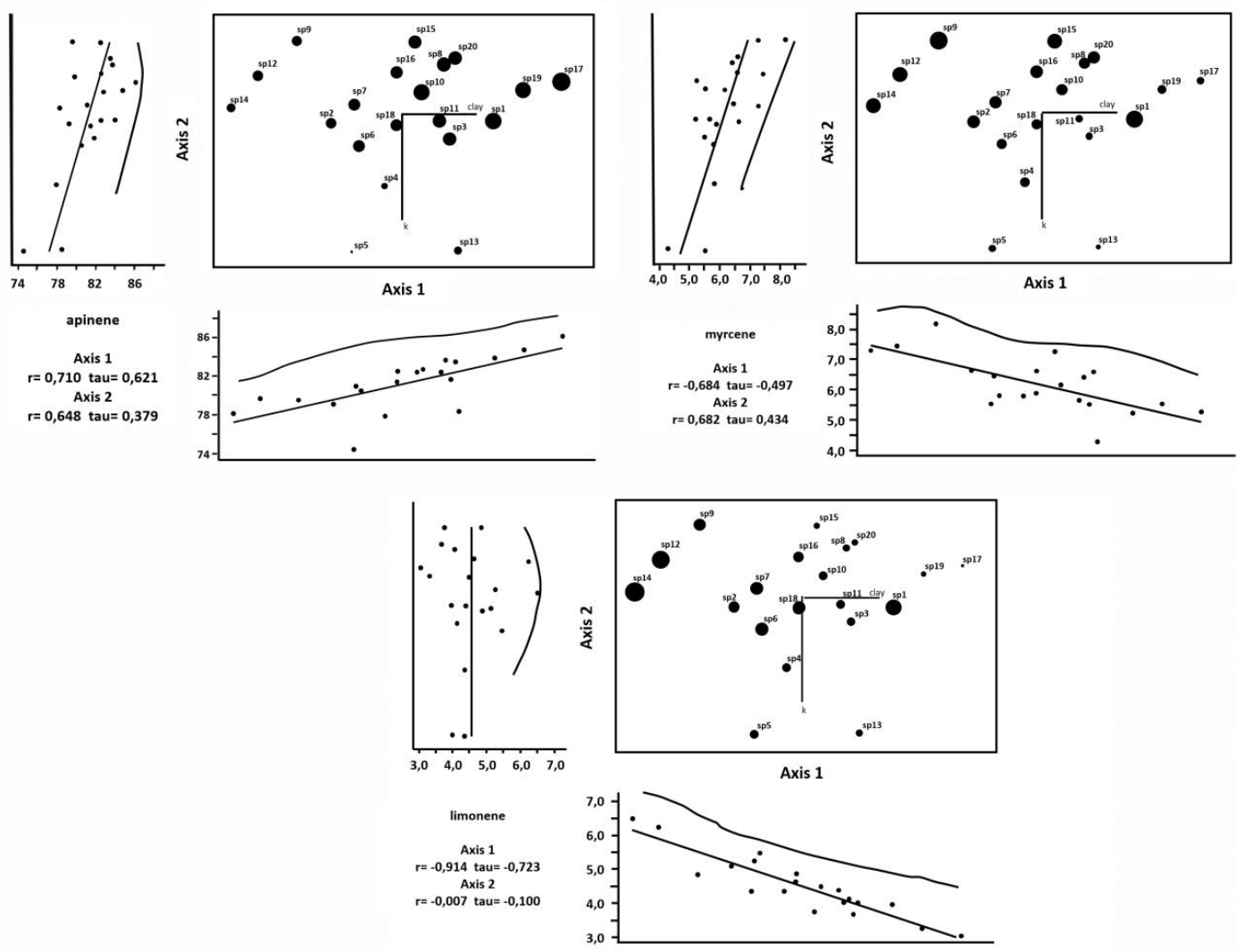

Figure 4. Correlation between major essential oil components and soil factors on PCA Axis 1-2 
As shown in Figure 4, a statistically significant correlation was found between PCA Axis 1 and clay only $(r=0.430)$ and between Axis 2 and potassium only $(r=-0.480)$. Clay percentage had a positive correlation with $\alpha$-pinene out of the essential oil components in the Crimean juniper leaves on Axis 1, which was the most explanatory one, and a negative correlation with myrcene and limonene.

In this study, the essential oil components in the leaves of Crimean juniper which has a considerable distribution area both in Turkey and across the world and the environmental variables were associated. Ecological site conditions in areas where the species is distributed at elevations between 500-2000 m in moderately and highly mountainous parts are that limestone is dominant with rocky-stony landform, mainly on upper slopes and undulating terrain. The mean radiation index and temperature index of the sampling plots show that the species is found mainly on the very shadowy and humid aspects but also prefer sunny aspects as soon as it finds the appropriate site conditions at the combination of other ecological factors. In general, these areas are very inclined, steep and precipitous and had shallow or moderately deep soils in terms of absolute soil depth. In a study conducted to explore the ecology of the species in the region, it was found that its distribution increased at an elevation of 800-1800 $\mathrm{m}$ where the surface stoniness intensified under dry climate conditions, while the ecological tolerance of Crimean juniper was higher especially on the shady aspects of these environments compared to Cedrus libani A. Rich and Pinus nigra Arnold (Özkan et al., 2010). In general, it was stated that Crimean juniper that is referred to as a cold and drought tolerant species (Sarangzai et al., 2015) preferred mainly the humid environments in the northern and western aspects of the inner parts of the Mediterranean Region of Turkey (Fontaine et al., 2007). On the other hand, it was also underlined that especially higher elevations and areas with valley characteristics were more appropriate for the distribution of this species compared to the lower elevations and flat terrains (Fisher and Gardner, 1995). Furthermore, it is known that Crimean juniper trees could adapt to areas with typical Mediterranean climate with hot summers and frost in winter under shallow soil conditions in the rocky and stony terrains of the very inclined or steep lands without suffering from any damage. That is because Crimean juniper is known to convert the restricted absolute depth conditions into physiologically appropriate forms by taking advantage of the cracked structure of the bedrock which is mainly dominated by limestone in these types of environments (Gülsoy and Özkan, 2013). Therefore we can conclude that the findings of this study regarding the distribution of this species are in accordance with other published studies.

The dominant soil type of the topsoil included in this study $(0-5 \mathrm{~cm})$ was loam and its derivatives, while they were classified as rich and humic soils in terms of organic matter content. In direct proportion to the rich humus content, the field capacity of these soils and wilting point were found to be high and the soils have a granular structure in general. Moreover, with respect to lime content, nearly all of these soils were classified as carbonated, poorly alkaline and saline-free soils. The $\mathrm{pH}$ of the soils collected from juniper sites were found to be mildly alkaline and the most common cation in the soils was $\mathrm{Ca}^{++}$, which can be explained by the high lime percentage depending on the limestone bedrock (Gülser et al., 2012).

In the study, forty one compounds were identified from the leaves of Crimean juniper and quantified, with $\alpha$-pinene $(81.3 \%)$, myrcene $(5.2 \%)$ and limonene $(4.5 \%)$ being the major components. All major components identified belonged to the monoterpene class. Topçu et al. (2005) found that the major essential components in 
leaves of Crimean juniper consists of $\alpha$ - pinene $(29.7 \%)$, cedrol $(25.3 \%)$ and $\alpha$ murolene $(4.4 \%)$, respectively. Furthermore, in another studies conducted in Iran and in south-east of R. Macedonia, $\alpha$-pinene $(32.3 \%, 33.8 \%)$ and cedrol $(13.1 \%, 24.4 \%)$ were found as major components in the leaves essential oil of Crimean juniper (Emami et al., 2011; Sela et al., 2015). On the contrary, Sela et al. (2015) found that sabinene and thujone were the predominant essential oil components in the samples from southwestern part of R. Macedonia. In a different study, $\alpha$-pinene $(36.0 \%), \beta$ - pinene $(30.2 \%)$ and limonene $(12.6 \%)$ were found as the major components in the leaves of the species (Nadir et al., 2013). It is clear that $\alpha$-pinene was found to be the major component in almost all of these studies, while differences were observed between the percentages of $\alpha$-pinene and those of the other components. This difference is considered to be due to the location where the samples were collected, harvest season, maturity stage and genetic factors (Salehi et al., 2010; Adams et al., 2013). As a matter of fact, it has been stated that these types of factors are also effective in the several chemical properties such as the phenolic content, antioxidant and sugar levels of plants (Ali et al., 2011; Skrovankova et al., 2015).

Finally, with regard to the association between the percentages of major essential oil components in the sampling plots and the environmental factors, the cluster and principal component analyses showed that primarily latitude as well as clay percentage and secondarily topographical position index, elevation and climate factors might have an effect. Adams et al. (2013) reported a partial effect of geographical variations in the essential oil components of Crimean juniper leaves sampled from Greece, Bulgaria, Turkey and Cyprus. No other study was found in the literature that explored the association between the essential oil properties of Crimean juniper leaves and environmental factors.

\section{Conclusions}

In conclusion, the findings of this study exhibited that environmental factors can have an impact on the essential oil components of the plants, whereas they are not so explanatory. The reason is that factors such as especially genetic variation of plant species, time of sample collection and methods applied have an impact on the type and percentage of these components in addition to the environmental factors as mentioned before. Therefore, there is a need for further studies with established standards on this matter in order to obtain clearer and precise results. It is possible that some secondary metabolites, such as volatile oils, can be assessed in some cases, such as climate change, environmental pollution etc., if clearer information is obtained from these studies.

Acknowledgements. We would like to thank Süleyman Demirel University Scientific Research Projects Coordination Unit for supporting our study under the project number SDÜ-BAPKB-4116-YL1-14. Moreover, the soil data were obtained simultaneously with the project numbered TUBITAK-112O814, for which we would also like to thank the relevant institutions and persons.

\section{REFERENCES}

[1] Adams, R. P., Tashev, A. N., Baser, K. H. K., Christou, A. K. (2013): Geographic variation in volatile leaf oils of Juniperus excelsa M. Bieb. - Phytologia 95(4): 279-285. 
[2] Ali, L., Svensson, B., Alsanius, B. W., Olsson, M. E. (2011): Late season harvest and storage of Rubus berries-Major antioxidant and sugar levels. - Scientia Horticulturae 129: 376-381.

[3] Bakkour, Y., El-Achi, N., Tabcheh, M., El-Nakat, H., El-Omar, F. (2013): Chemical composition and antioxidant activities of the essential oils from green and ripe berries of Juniperus excelsa growing in Lebanon. - International Journal of Pharmacy and Life Sciences 4: 2362-2367.

[4] Beers, T. W. Dress, P. E. Wensel, L. C. (1966): Notes and observations: aspect transformation in site productivity research. - Journal of Forestry 64: 691-692.

[5] Benli, H. (2016): Potential application of solar water heaters for hot water production in Turkey. - Renewable and Sustainable Energy Reviews 54: 99-109.

[6] Bouyoucos, G. J. (1951): A recalibration of the hydrometer method for making mechanical analysis of soils. - Agronomy Journal 43: 434-438.

[7] Bro, R., Smilde, A. K. (2014): Principal component analysis. - Analytical Methods 6(9): 2812-2831.

[8] Bush, P. R. (1970): A rapid method for the determination of carbonate carbon and organic carbon. - Chemical Geology 6: 59-62.

[9] Cassell, D. K., Nielson, D. R. (1986): Field Capacity and Available Water Capacity. - In: Klute, A. (ed.) Agronomy No. 9: Methods of Soil Analysis: Physical and mineralogical methods. Am. Soc. Agron. and Soil Sci. Soc. Am., Madison, WI, pp. 911-913.

[10] Chapman, H. D. (1965): Cation-Exchange Capacity. - In: Black, C. A. (ed.) Methods of Soil Analysis. Part 2. Chemical and Microbiological Properties. American Society of Agronomy, Madison, WI, pp. 891-901.

[11] Emami, A. S., Abedindo, B. F., Khayyat, M. H. (2011): Antioxidant activity of the essential oils of different parts of Juniperus excelsa M. Bieb. subsp. excelsa and $J$. excelsa M. Bieb. subsp. polycarpos (K. Koch) Takhtajan (Cupressaceae). - Iran Journal of Pharmaceutical Research 10: 799-810.

[12] Eriksson, C. P., Holmgren, P. (1996): Estimating stone and boulder content in forest soils evaluating the potential of surface penetration methods. - Catena 28: 121-134.

[13] Fakir, H. (2014): Türkiye'nin Doğal-Egzotik Ağaç ve Çalıları. - Turkish General Directorate of Forestry Publication No. 1, Ankara, pp. 673-702.

[14] Faydaoğlu, E., Sürücüoğlu, M. S. (2011): History of the use of medical and aromatic plants and their economic importance. - Kastamonu Univ. Journal of Forestry Faculty 11: 52-67.

[15] Fejér, J., Grul'ová, D., Elıašová, A., Kron, I., De Feo, V. (2018): Influence of environmental factors on content and composition of essential oil from common juniper ripe berry cones (Juniperus communis L.). - Plant Biosystems - An International Journal Dealing with all Aspects of Plant Biology. DOI: 10.1080/11263504.2018.1435577.

[16] Fick, S. E., Hijmans, R. J. (2017): WorldClim 2: new 1-km spatial resolution climate surfaces for global land areas. - International Journal of Climatology 37(12): 4302-4315.

[17] Fisher, M., Gardner, A. S. (1995): The status and ecology of a Juniperus excelsa subsp. polycarpos woodland in the northern mountains of Oman. - Vegetatio 119: 33-51.

[18] Fontaine, M., Aerts, R., Özkan, K., Mert, A., Gülsoy, S., Süel, H., Waelkens, M., Muys, B. (2007): Elevation and exposition rather than soil types determine communities and site suitability in Mediterranean mountain forests of southern Anatolia, Turkey. - Forest Ecology and Management 247: 18-25.

[19] Gende, L., Maggi, M., Van Baren, C., Di Leo, A., Bandoni, A., Fritz, R., Eguaras, M. (2010): Antimicrobial and miticide activities of Eucalyptus globulus essential oils obtained from different Argentine regions. - Spanish Journal of Agricultural Research 8(3): 642-650.

[20] Göze, I., Göze, Ö. F., Yelkovan, I., Çetinus, Ş. A., Saygin, H., Ercan, N. (2017): The Review of certain in vivo antioxidant effects on essential oils of Origanum minutiflorum 
O Schwarz-Ph Davis, Juniperus excelsa Bieb. subsp. excelsa and histopathologic changes. - Revista Brasileira de Ciência Avícola 19(2): 333-338.

[21] Gülser, F., Çı̆g, A., Türkoğlu, N. (2012): The Determination of nutrient contents of native juniper (Juniperus excelsa Bieb.) and soil properties of plant growing areas in Van. Iğdır University Journal of the Institute of Science and Technology 2: 93-98.

[22] Gülsoy, S., Merdin, A. (2017): Essential oil yield and components of juniper (Juniperus excelsa Bieb.) leaves. - Bilge International Journal of Science and Technology Research 1(2): 119-128.

[23] Gülsoy, S. Özkan, K. (2013): Determination of environmental factors and indicator plant species for site suitability assessment of Crimean juniper in the Acipayam District, Turkey. - Sains Malaysiana 42: 1449-1457.

[24] Höferl, M., Stoilova, I., Schmidt, E., Wanner, J., Jirovetz, L., Trifonova, D., Krastev, L., Krastanov, A. (2014): Chemical composition and antioxidant properties of Juniper berry (Juniperus communis L.) essential oil. Action of the essential oil on the antioxidant protection of Saccharomyces cerevisiae model organism. - Antioxidants 3(1): 81-98.

[25] Jackson, M. L. (1958): Soil Chemical Analysis. -Prentice-Hall, Inc. Englewood Cliffs, NJ.

[26] Ložienè, K., Venskutonıs, P. R. (2016): Juniper (Juniperus communis L.) Oils. - In: Preedy, V. (ed.) Essential Oils in Food Preservation Flavor and Safety. Academic Press, Amsterdam, pp. 495-500.

[27] McCune, B., Keon, D. (2002): Equations for potential annual direct incident radiation and heat load. - Journal of Vegetation Science 13: 603-606.

[28] Mert, A., Şentürk, Ö., Güney, C. O., Akdemir, D., Özkan, K. (2013): Mapping of Some Distal Variables Available for Mapping Habitat Suitabilities of the Species: A Case Study of Buldan District. - In: Atalay, İ., Efe, R. (eds.) GeoMed 2013 The 3rd International Geography Symposium, 10-13 June, 2013, Kemer Antalya, pp. 210,

[29] Moein, M. R., Ghasemi, Y., Moein, S., Nejati, M. (2010): Analysis of antimicrobial, antifungal and antioxidant activities of Juniperus excelsa M. B. subsp. polycarpos (K. Koch) Taghtajan essential oil. - Pharmacognosy Research 2(3): 128-131.

[30] Nadir, M., Rasheed, M., Ahmed, A. (2013): Comparative studies on the phytochemistry of essential oil from needles and berries of Juniperus excelsa M. Bieb. - Journal of the Chemical Society of Pakistan 35(2): 438-443.

[31] Orhan, N., Akkol, E., Ergun, F. (2012): Evaluation of anti inflammatory and antinociceptive effects of some Juniperus species growing in Turkey. - Turkish Journal of Biology 36: 719-726.

[32] Özkan, K., Gulsoy, S., Aerts, R., Muys, B. (2010): Site properties for Crimean juniper (Juniperus excelsa) in semi-natural forests of south western Anatolia, Turkey. - Journal of Environmental Biology 31: 97-100.

[33] Salehi, S. P., Mirzaa, M., Calagaria, M., Adams, R. P. (2010): Effects drying and harvest season on the essential oil composition from foliage and berries of Juniperus excelsa. Industrial Crops and Products 32: 83-87.

[34] Sandler, A., Meunier, A., Velde, B. (2015): Mineralogical and chemical variability of mountain red/brown Mediterranean soils. - Geoderma 239: 156-167.

[35] Sarangzai, A. M., Siddiqui, M. F., Ahmed, M., Hussain, M. I., Laghari, S. K., Ahmed, A. (2015): Relationship between soil properties and natural regeneration pattern of Juniperus excelsa forest in Ziarat, Balochistan. - Pakistan Journal of Botany 47(3): 905-910.

[36] Sarstedt, M., Mooi, E. (2014): Cluster Analysis. - In: Mooi, E., Sarstedt, M. (eds.) A Concise Guide to Market Research. Springer, Berlin, Heidelberg, pp. 273-324.

[37] Sela, F., Karapandzova, M., Stefkov, G., Cvetkovikj, I., Kulevanova, S. (2015): Chemical composition and antimicrobial activity of essential oils of Juniperus excelsa Bieb. (Cupressaceae) grown in R. Macedonia. - Pharmacognosy Research 7(1): 74-80. 
[38] Skrovankova, S., Sumczynski, D., Mlcek, J., Jurikova, T., Sochor, J. (2015): Bioactive compounds and antioxidant activity in different types of berries. - International Journal of Molecular Sciences 16(10): 24673-24706.

[39] Spietelun, A., Marcinkowski, Ł., De La Guardia, M., Namieśnik, J. (2013): Recent developments and future trends in solid phase microextraction techniques towards green analytical chemistry. - Journal of Chromatography 1321: 1-13.

[40] Topçu, G., Gören, A. C., Bilsel, G., Bilsel, M., Çakmak, O., Schilling, J., Kinston, D. G. I. (2005): Cytotoxic activity and essential oil composition of leaves and berries of Juniperus excelsa. - Pharmaceutical Biology 43: 125-128.

[41] Weiss, A. (2001): Topographic position and landforms analysis. -Poster Presentation, ESRI User Conference, San Diego, CA, pp. 200-200. 